conscious of its 'object' not as consciencing, if I may use this word, but as conscienced." Neither may it be urged "that if there is an awareness of awareness, there must by the same token be an awareness of awareness of awareness, and so on ad infinitum,' for 'this way madness lies.'

In the second article the query is made as to what sort of continuity belongs to consciousness, a distinction being noted between that which is continuous empirically and that which must be continuous metaphysically. "If consciousness is . . . empirically continuous it must be either that all the objects which crop up in the course of experience are evidently cases of consciousness, or that they come to us having a gapless fringe or penumbra of consciousness, or that the continuity is maintained by means of a combination of objects characterized as consciousness and of consciousness-penumbra." It is presumably the first alternative which is meant by the advocates of continuity. "But we can not continually ' hold up' life in the interest of philosophy, and the section of experience through which consciousness may, possibly, have been continuous, must be followed by sections full of practical interests and physical energy, in which consciousness very probably does not exist, consciousness, that is, as one type of 'that' along with other 'thats,' and therefore as something identifiable and distinguishable. Accordingly, if there is any truth in this way of describing the facts, consciousness is not empirically continuous, but occasional and intermittent." Under which head, then, the empirical or the metaphysical, the is or the must be, does this continuity occur, and has the consciousness which is continuous ' any subjective character' or is it simply a "psychological word for 'empirical situation" "?

UNIVERSITY OF TENNESSEE.

Robert Morris Ogden.

The Subconscious Factors of Mental Process Considered in Relation to Thought. A. M. Bodkis. Mind, April, I907; July, 1907 .

Using feeling as an expression for emotional and sense experience the author asks the fundamental question: Is there a difference between sense and cognition - between feeling and knowing? There is a fundamental difference, though in our focal consciousness the two are always conjoined. Sense experience (feeling) must be conceived of as containing the material for the knowledge of relations.

The analysis of the concept of judgment brings out the author's idea of the distinction between sensations and ideas. The predicates of our judgments constitute a world of ideas - a world of Platonic 
ideas as conceived by Lotze. The bewildering content of sense experience is bound together by the efforts of the mind into unchangeable conceptions. These conceptions constitute an unfailing treasury for the predicates of our judgments. Judgment is the union of a perception with one of the ideals of the mind. It is a process of apperception in the Herbartian sense of the word. It seems to be the author's idea that the distinction between ideas and sensations is that between the above mentioned world of ideas and the impressions received from the objects presented to consciousness. In the process of perception there is no ideal element except in so far as the thing perceived is related to one of the unchanging conceptions in the world of ideas. There are sensations which are not related to any of the unchangeable concepts. They hover in the background of consciousness. When we discover what they are and can name them we relate them to some concept in the world of ideas.

The process of reasoning of necessity involves judgment. This, as we have seen, means a union of some perception with one of the concepts constituting the subject's world of ideas. But the judgment of inference is not merely grouped with other judgments. "It must be conceived as normally made for the sake of some further consequence - some value it will have in the guidance of actions - immediate or remote" (p. 366).

The foundation for our conclusion is not al ways explicitly known. Indeed men are often convinced as to some point and cannot clearly state why. The problem arises, whence comes this conviction from unconscious cerebral conditions? Or does it arise from a mental content which affects the mind as a whole, but whose separate elements remain subconscious? The author maintains that the former alternative is insufficient to account for the facts. In developing the latter he shows how subconscious and implicit factors of our thought become fully conscious and explicit.

UNIVERSITY OF CALIFORNIA.

T. V. MOORE.

\section{PERCEPTION AND REALITY.}

In What Sense Two Persons Perceive the Same Thing. G. S. Fullerton. Phil. Rev., I907, XVI., 506-518.

Before taking up the specific problem indicated by the title, the author first considers in what sense a person may be said to perceive twice the same thing. The conclusion is that we do not mean that we have the same experience again, for we can never have the same 